\title{
QUANTUM CHEMICAL STUDIES OF CHITOSAN NANOPARTICLES AS ANTICANCER DRUG DELIVERY SYSTEM FOR DECITABINE
}

\author{
MAHNAZ RAHBAR, ${ }^{*}$ ALI MORSALI,${ }^{* *}$ MOHAMMAD REZA BOZORGMEHR ${ }^{*}$ and \\ S. ALI BEYRMABADI* \\ *Department of Chemistry, Mashhad Branch, Islamic Azad University, Mashhad, Iran \\ *Research Center for Animal Development Applied Biology, Mashhad Branch, \\ Islamic Azad University, Mashhad 917568, Iran \\ ๔Corresponding author: A. Morsali, morsali@mshdiau.ac.ir
}

Received February 2, 2020

Applying DFT functionals (B3LYP and M06-2X), ten structures for the adsorption of decitabine medicine (DC) onto a chitosan nanocarrier (CHIT) were studied. The solvation and binding energies were evaluated in solution (water) and gas phases. Here, we used the negative values of binding energies to represent the energetic stability of ten structures (CHIT/DC1-10). The solvation energies showed that the solubility of DC drug increased near the CHIT nanocarrier and thus it could be a main element for the applicability of any nanocarrier. Here, the quantum molecular descriptors revealed that the toxicity of DC in ten structures was reduced to some extent and its own reactivity increased. Analyzing the data obtained by the Atoms in Molecules (AIM) method for CHIT/DC1-10, it has been found that the hydrogen bonds are an essential element in the non-covalent functionalization of CHIT with DC.

Keywords: chitosan, decitabine, nanocarrier, DFT, Schiff base, decitabine drug, hydrogen bonds

\section{INTRODUCTION}

For decreasing the issues of anticancer drugs, such as low selectivity, high toxicity, side effects, water insolubility and poor stability, many studies have already been conducted on drug delivery systems. Many of these studies have been carried out on carbon-based nanocarrier systems, like carbon nanotubes, ${ }^{1-5}$ dendrimers, ${ }^{6}$ liposomes, ${ }^{7}$ drug-polymer conjugates, ${ }^{8}$ C60 and chitosan. ${ }^{9-10}$ Chitosan is a good drug carrier obtained from the chitin polysaccharide.

Nanostructures of chitosan (chitosan nanoparticles) have already been applied in drug delivery systems due to their properties, such as biocompatibility, non-toxicity, high permeability, renewability, solubility in mild acid, low allergenicity, and biodegradability of surface functional groups $\left(\mathrm{NH}_{2}\right.$ and $\left.\mathrm{OH}\right){ }^{11-16}$ Chitosan has many properties that are linked to its primary amine group, including hydrogen bond formation, muco-adhesion, cationic nature, controlled drug release, antimicrobial activity, and permeation enhancement. ${ }^{11,12}$ Different forms of chitosan and its derivatives have been used as gels, films, fibers, beads, solutions and powder. ${ }^{10}$
Chitosan nanoparticles have been successfully used as carrier molecules as they demonstrated that lower doses of anticancer drugs are sufficient, thus decreasing their side effects. Thus, chitosan has been used as carrier for various anticancer drugs, such as decitabine, ${ }^{18-21}$ doxorubicin, ${ }^{21-23}$ cisplatin, ${ }^{24,25}$ nifedipine, ${ }^{26,27}$ methotrexate, ${ }^{27,28}$ melphalan, ${ }^{29}$ paclitaxel, ${ }^{30,31}$ artemisinin, ${ }^{32}$ 10hydroxycamptothecin, ${ }^{33}$ capecitabine, ${ }^{34}$ etoposide ${ }^{35}$ gemcitabine, ${ }^{36,37}$ and mercaptopurine. ${ }^{38}$ In addition, chitosan has been also reported as drug carrier for Alzheimer's illness, ${ }^{39} \mathrm{HIV},{ }^{40,41}$ inflammation ${ }^{42}$ and bacteria. ${ }^{43}$

We used quantum computing since it is a really powerful tool for analyzing drug delivery systems. ${ }^{44-47}$ In this article, we used quantum chemical calculations to review non-covalent functionalization of chitosan with decitabine. Researchers can benefit from the results to develop and apply targeted anticancer drugs and shorten the trial-and-error process in the lab. Morever, decitabine (trade name Dacogen), or 5aza-2-deoxycytidine, could act as a nucleic acid synthesis inhibitor. This is a drug for treatment of

Cellulose Chem. Technol., 54 (7-8), 679-688(2020) 
myelodysplastic syndromes, a category of situations where certain blood cells are dysfunctional, as well as for acute myeloid leukemia.

\section{EXPERIMENTAL}

\section{Computational method}

In this paper, the GAUSSIAN 09 package $^{48}$ was applied to optimize the key structures in gas phase and solution phase at M06- $2 X^{49} / 6-31 G(d, p)^{50}$ and

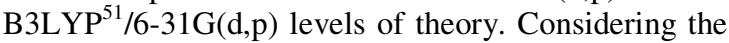
implicit solvent effects, the polarized continuum model (PCM) was utilized. ${ }^{52,53}$ In addition, we used the standard convergence criteria for optimization of the molecular structures. For all species, we optimized the degrees of freedom. Furthermore, we considered zeropoint corrections. Having only one imaginary frequency of the Hessian, we examined these transition states.

Quantum molecular descriptors enable examining chemical reactivity and stability; $\eta$ as global hardness represents the resistance of one particle against the modification in its electronic structure:

$\eta=(\mathrm{I}-\mathrm{A}) / 2$

in which $I=-E_{\text {HOMO }}$ and $A=-E_{L U M O}$ are the ionization potential and the electron affinity, respectively. The electrophilicity index $(\omega)^{54}$ can be evaluated by:
$\omega=(1+A)^{2} / 8 \eta$

We used the QTAIM (Quantum Theory of Atoms in Molecules) calculations to study the hydrogen bond. AIMAll software55 was applied for QTAIM calculations. Topological parameters as electron density $\rho(r) 56$ were used in QTAIM. The nature of the bonds in various species was identified to analyze various values of electron density, such as $\mathrm{Vb}$ (potential energy density), Gb (kinetic energy density), $\nabla 2 \rho$ (Laplacian of electron density) and $\mathrm{Hb}$ (total energy density) at a bond critical point (BCP).

\section{RESULTS AND DISCUSSION}

Using a polymer sequence with 3 monomer units, chitosan nanoparticles were modeled. The optimized configuration of the chitosan nanoparticle (CHIT) and decitabine (DC) are presented in Figure 1. The interaction of decitabine, which consists of one $\mathrm{CO}$, one $\mathrm{NH}_{2}$, two $\mathrm{OH}$, one $\mathrm{O}$ and three $\mathrm{N}$ functional groups, with the chitosan nanoparticle has been evaluated for ten different structures (CHIT/DC1-10). The optimized configurations of CHIT/DC1-5 and CHIT/DC5-10 are illustrated in Figures 2 and 3, respectively (in aqueous solution at M06-2X/6$31 \mathrm{G}(\mathrm{d}, \mathrm{p})$ level of theory).

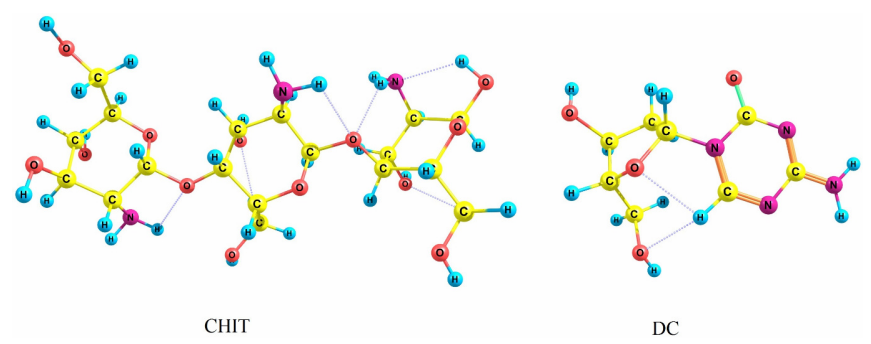

Figure 1: Optimized structures of DC and CHIT

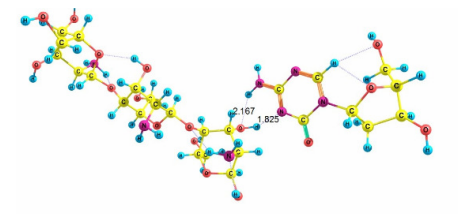

CHIT/DC1

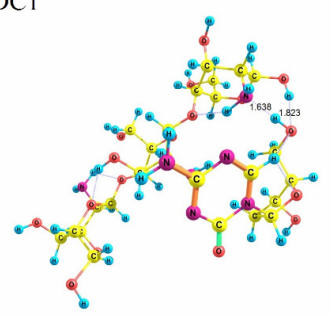

CHIT/DC4
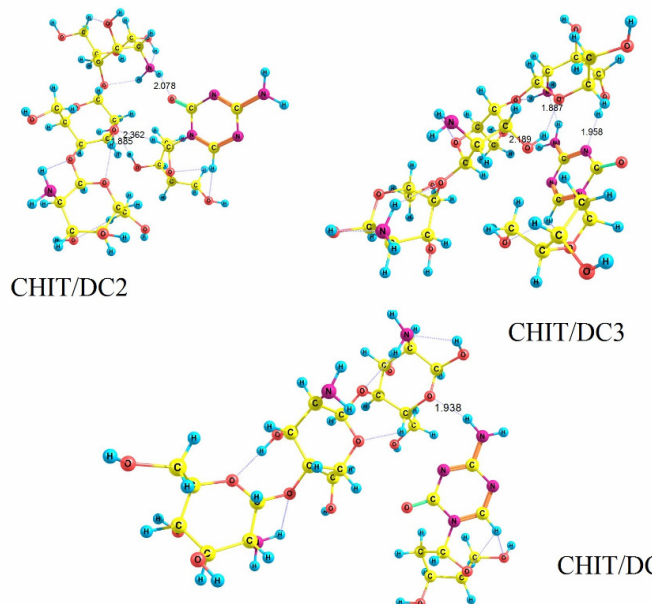

CHIT/DC3

Figure 2: Optimized structures of CHIT/DC1-5 

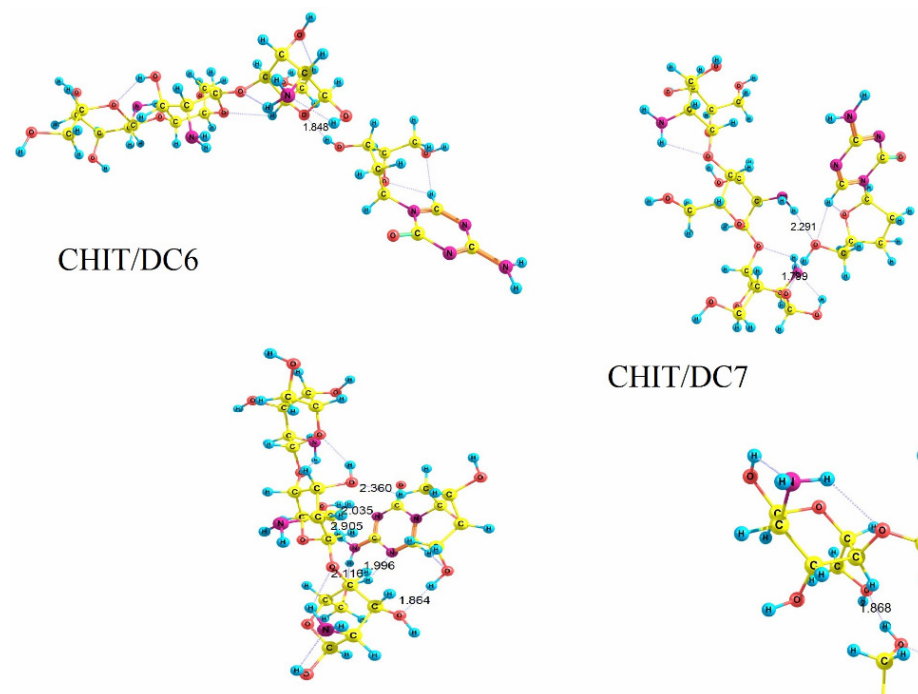

CHIT/DC7

CHIT/DC8

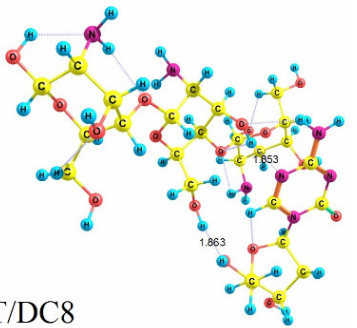

CHIT/DC9

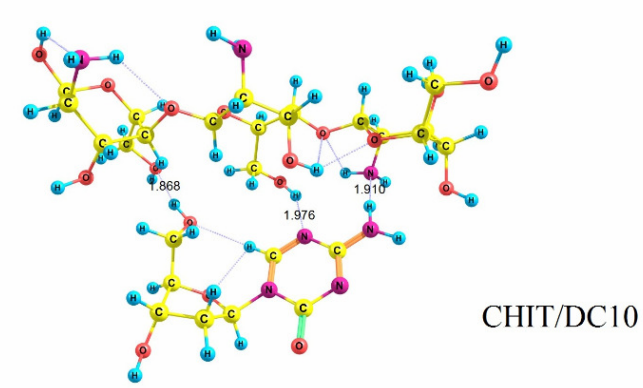

Figure 3: Optimized structures of CHIT/DC6-10

Table 1

Binding $(\Delta \mathrm{E})$ and solvation $\left(\Delta \mathrm{E}_{\mathrm{solv}}\right)$ energies $\left(\mathrm{kJ} \mathrm{mol}^{-1}\right)$ for optimized geometries

\begin{tabular}{|c|c|c|c|c|c|c|}
\hline Species & $\Delta E_{\text {solv }}^{\text {EDLW }}$ & $\Delta E_{S D V}^{M D-2 X}$ & $\Delta E_{\text {Gack }}^{\text {gas }}$ & $\Delta E_{G Z Y Y}^{R_{2} O}$ & $\Delta E_{M O S-2 A}^{G Q S}$ & $\Delta E_{M 0 S-2 A}^{H_{2} O}$ \\
\hline $\mathrm{DC}$ & -65.8 & -67.3 & - & - & - & - \\
\hline CHIT & -87.9 & -85.8 & - & - & - & - \\
\hline CHIT/DC1 & -153.5 & -159.6 & -56.0 & -55.8 & -66.2 & -72.8 \\
\hline CHIT/DC2 & -148.5 & -120.5 & -65.5 & -60.3 & -130.5 & -98.0 \\
\hline CHIT/DC3 & -118.7 & -127.4 & -106.8 & -71.8 & -152.5 & -126.9 \\
\hline CHIT/DC4 & -149.0 & -87.9 & -75.0 & -70.3 & -154.9 & -89.7 \\
\hline CHIT/DC5 & -149.4 & -84.5 & -47.5 & -43.2 & -129.1 & -60.5 \\
\hline CHIT/DC6 & -138.7 & -162.9 & -60.9 & -45.8 & -53.9 & -63.7 \\
\hline CHIT/DC7 & -148.1 & -157.8 & -61.5 & -55.9 & -74.5 & -79.2 \\
\hline CHIT/DC8 & -165.8 & -137.2 & -68.6 & -80.7 & -125.2 & -109.4 \\
\hline CHIT/DC9 & -142.9 & -115.9 & -83.2 & -72.4 & -144.6 & -107.5 \\
\hline CHIT/DC10 & -145.7 & -117.4 & -93.9 & -85.8 & -163.0 & --127.3 \\
\hline
\end{tabular}

Interaction (binding) energies $(\Delta \mathrm{E})$ for CHIT/DC1-10 structures were calculated using the following equation:

$$
\Delta E=E_{\mathrm{CHT} / \mathrm{DC1}-10}-\left(E_{\mathrm{CHT}}+E_{D C}\right)
$$

Table 1 shows the $\Delta \mathrm{E}$ values at both levels of B3LYP and M06-2X in aqueous solution and gas phase. The $\Delta \mathrm{E}$ values calculated by M06-2X functional are more negative than those of B3LYP. Unlike B3LYP, dispersion corrections ${ }^{57}$ are considered by M06-2X functional; therefore, these interactions (dispersion corrections) emerge as interesting forces. The $\Delta \mathrm{Es}$ in gas phase (-
$119.44 \mathrm{~kJ} \mathrm{~mol}^{-1}$ and $-71.89 \mathrm{~kJ} \mathrm{~mol}^{-1}$ on average at M06-2X and B3LYP, respectively) are more negative than those in aqueous solution $(-93.5 \mathrm{~kJ}$ $\mathrm{mol}^{-1}$ and $-64.2 \mathrm{~kJ} \mathrm{~mol}^{-1}$ on average at M06-2X and B3LYP, respectively) because the solvent molecules compete with the drug molecules for adsorption. On the other hand, the interaction energies are negative for both functionals, showing that the surface adsorption of the decitabine drug onto the chitosan carrier is good.

The $\Delta$ Es were determined by the orientation of decitabine in accordance with the adsorbent. Based on the results obtained by both B3LYP and 
M06-2X functionals, among the 10 different structures, CHIT/DC10 has the most negative connection energy in aqueous solution (probably the most stable one), where the $\mathrm{NH}_{2}$ and $\mathrm{N}$ functional groups of DC interact with the $\mathrm{NH}_{2}$ and $\mathrm{OH}$ functional groups of CHIT, respectively (Fig. 3). Concerning stability, the CHIT/DC3 structure is positioned as the second one in aqueous solution. The range of binding energy values is in agreement with the values obtained from the interaction of chitosan with other biological and therapeutic agents. ${ }^{58-60}$ Due to the large negative $\Delta \mathrm{Es}$, it is predicted that sufficient drug loading will be achieved. ${ }^{61-63}$

The solvation energies $\left(\Delta \mathrm{E}_{\text {wolv }}\right)$ were evaluated using the following equation (Table 1 ):

$\Delta E_{\text {row }}=E_{\text {gq }}-E_{\text {gas }}$

where $E_{\text {gas }}$ and $E_{\text {aq }}$ show the energies (sum of electronic and zero-point energies) in the gas phase and solution phase, respectively.

An appropriate carrier for a specific drug should increase the solubility of the drug in aqueous solution. The $\Delta \mathrm{E}_{\text {golv }}$ of DC $(-67.3 \mathrm{~kJ}$ $\mathrm{mol}^{-1}$ and $-65.8 \mathrm{~kJ} \mathrm{~mol}^{-1}$ at M06-2X and B3LYP, respectively) becomes more negative in the current presence of chitosan $\left(-127.1 \mathrm{~kJ} \mathrm{~mol}^{-1}\right.$ and $146.0 \mathrm{~kJ} \mathrm{~mol}^{-1}$ on average at M06-2X and B3LYP, respectively), so the solubility of DC is increased by CHIT. The primary reason for the increase in solubility and strong interactions relates to the forming of hydrogen bonds between the drug and the carrier, which is discussed in detail within the next part by the quantum theory of atoms in molecules. Considering the intermolecular hydrogen bonds more closely, charge density properties are used. The interactions were evaluated by QTAIM research. The character and strength of an interaction could be displayed by $\nabla^{2} \rho(r)$ and $\rho(r)$, respectively. Nevertheless, the signs of $\nabla^{2} \rho$ and $H_{b}$ present the nature of the interactions. If, $\left(\nabla^{2} \rho>0, H_{b}>0\right)$, $\left(\nabla^{2} \rho>0, H_{b}<0\right)$ and $\left(\nabla^{2} \rho<0, H_{b}<0\right)$, then weak, medium and strong interactions are expected, respectively. ${ }^{64}$ The character of an interaction can be defined by $-G_{b} / V_{b}$. For $-G_{b} / V_{b}>1$ and $0.5<-G_{b} / V_{b}<1$, non-covalent and partially covalent characters are predicted, respectively.

The molecular graphs of CHIT/DC1-5 and CHIT/DC 6-10 in aqueous solution at M06-2X/6$31 \mathrm{G}^{* *}$ level of theory are shown in Figures 4 and 5 , respectively. The atoms participating in the interactions will be marked in the figures. The $\rho(\mathrm{r}), \nabla^{2} \mathrm{p}(\mathrm{r}), H_{b}, G_{\mathrm{b}}, V_{b}$ and $-G_{b} / V_{b}$ values for these interactions are displayed in Table 2 (at M06-2X/6-31G** level of theory in aqueous solution). The hydrogen bond energy $\left(E_{H E}\right)$ continues to be approximated by the following equation:

$$
E_{H B}=\frac{V_{b}}{2}
$$

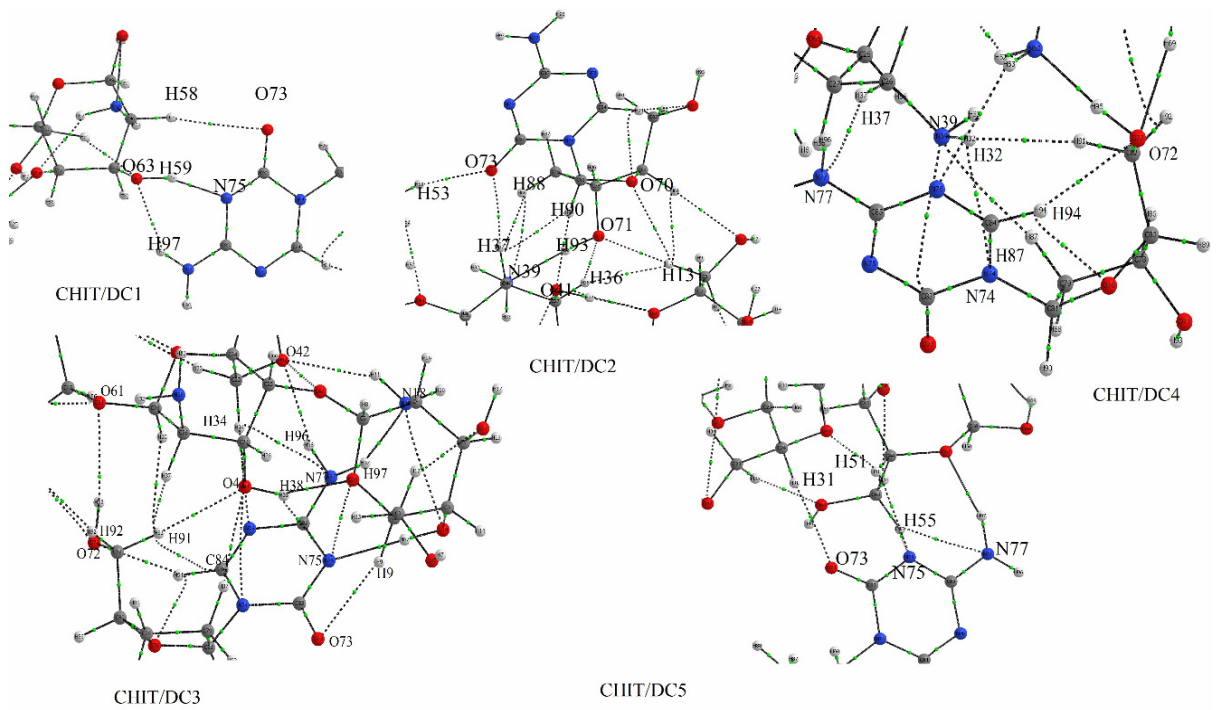

Figure 4: Molecular graph of CHIT/DC1-5; small green spheres and dotted lines relate to the bond critical points (BCP) and the bond paths, respectively 


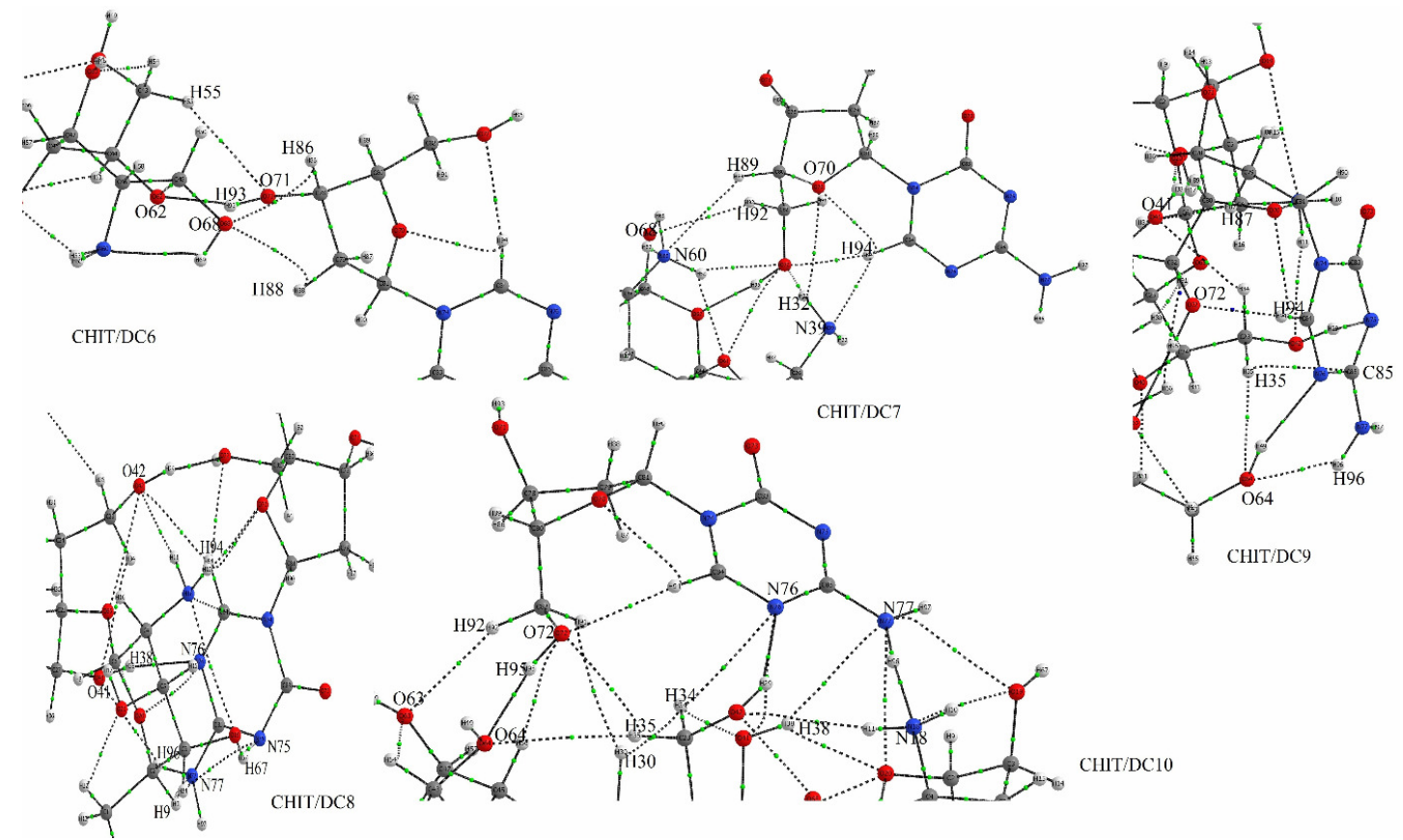

Figure 5: Molecular graph of CHIT/DC6-10; small green spheres and dotted lines relate to the bond critical points (BCP) and the bond paths, respectively

In the structures, we face two forms of hydrogen bonds, i.e., $\mathrm{O}-\mathrm{H}$ and $\mathrm{N}-\mathrm{H}$. We started with the most stable species (CHIT/DC10), where the $\mathrm{NH}_{2}$ and $\mathrm{N}$ functional groups of DC approach the $\mathrm{NH}_{2}$ and $\mathrm{OH}$ functional groups of CHIT, respectively. The H96 $=\mathrm{N} 18$ $\left(E_{H g}=-31.3 \mathrm{kJmol}^{-1}\right) \quad$ and $\quad \mathrm{H} 95 \cdots \mathrm{O} 64$ $\left(E_{H Q}=-30.8 \mathrm{k}^{\mathrm{m}} \mathrm{mol}^{-\mathrm{i}}\right) \quad$ connections with $\nabla^{2} p>0, H_{b}<0,0.5<-G_{b} / V_{b}<1$ are medium hydrogen bonds, in which the first one $(\mathrm{H} 96 \times \mathrm{N} 18)$ with $-G_{b} / V_{b}=0.9270$ is the strongest hydrogen bond in all the structures. The $\mathrm{H} 56=\mathrm{O} 72, \mathrm{H} 38 \cdots \mathrm{N} 77, \mathrm{H} 37 \cdots \mathrm{O} 72, \mathrm{H} 92 \cdots \mathrm{O} 63$, $\mathrm{N} 76^{*=\mathrm{O}} 41$ and $\mathrm{H} 34^{-\cdots \mathrm{N}} \mathrm{N6}$ interactions with $\nabla^{2} \rho>0, H_{b}>0$ and $-G_{b} / V_{b}>1$ relate to weak hydrogen bonds. Because of this structure, the sum of the hydrogen bond energies $\left(\sum_{i=1}^{8} E_{W B}^{b}\right)$ is

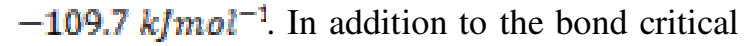
points of the hydrogen bonds, there are two other interactions between oxygen and nitrogen (N77$\mathrm{O} 19$ and N77-O20), as seen in Figure 5 (CHIT/DC10).

In CHIT/DC3, the second most stable configuration $\left(\sum_{i=1}^{i} E_{H B}^{i}=-118.9 \mathrm{~kJ} \mathrm{~mol}^{-1}\right) \mathrm{N}$ and $\mathrm{NH}_{2}$ functional groups of DC approach the
$\mathrm{OH}$ and $\mathrm{O}$ functional groups of CHIT. This structure provides medium hydrogen bonds, the most powerful of which is the H97**N18 $\left(E_{H E}=-34.3 \mathrm{kJmol}^{-1}\right)$. Three additional interactions (H34 $\cdots \mathrm{N} 77, \mathrm{H} 18 \cdots \mathrm{O} 19, \mathrm{H} 96=\mathrm{O} 42$, $\mathrm{H} 92 \cdots \mathrm{O} 61$ and $\mathrm{H} 94 \cdots \mathrm{O} 72$ ) will be classified as weak hydrogen bonds. One of them is related to $\mathrm{O}-\mathrm{H}$ interaction.

The third most stable species will be CHIT/DC2 $\quad\left(\sum_{i=1}^{8} E_{H B}^{i}=-111.2 \mathrm{k}^{i} \mathrm{~mol}^{-1}\right)$, where the $\mathrm{OH}$ and $\mathrm{CO}$ functional groups of $\mathrm{DC}$ connect to the $\mathrm{CH}_{2} \mathrm{OH}$ and $\mathrm{NH}_{2}$ functional groups of CHIT, respectively. In this particular structure, three medium hydrogen bonds are distinguished. CHIT/DC1 $\left(\sum_{i=1}^{3} E_{H B}^{i}=-63.3 \mathrm{k}^{i} \mathrm{~mol}^{-1}\right)$ has two medium and one weak hydrogen bond. Within it, the $\mathrm{NH}_{2}$ functional groups of $\mathrm{DC}$ connect to the $\mathrm{CH}_{2} \mathrm{OH}$ functional groups of CHIT.

We actually found that CHIT/DC8 $\left(\sum_{\mathrm{i}}^{\mathrm{N}} \mathrm{E}_{\mathrm{HE}}^{\mathrm{i}}=-85.9 \mathrm{kJmol}^{-1}\right), \quad$ includes 1 medium hydrogen bond (H38*N76) with $E_{\text {HB }}=-34.9 \mathrm{~kJ} \mathrm{~mol}^{-1}$, where the $\mathrm{NH}_{2}$ functional group of DC approaches the $\mathrm{OH}$ functional group of CHIT. 
MAHNAZ RAHBAR et al.

Table 2

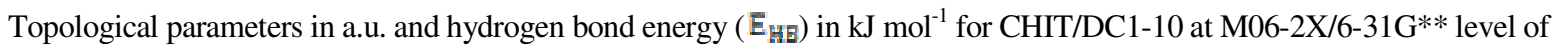
theory

\begin{tabular}{|c|c|c|c|c|c|c|c|}
\hline Atoms & $\rho(r)$ & $\nabla^{2} \rho(r)$ & $G_{k}$ & $v_{p}$ & $H_{\mathrm{z}}$ & $-\sigma_{1} v_{b}$ & $\bar{s}_{g z}$ \\
\hline \multicolumn{8}{|c|}{ CHIT/DC1 } \\
\hline $\mathrm{H} 58-\mathrm{O} 73$ & 0.0070 & 0.0226 & 0.0050 & -0.0044 & 0.0006 & 1.1388 & -5.8 \\
\hline H59 - N75 & 0.0399 & 0.1018 & 0.0275 & -0.0296 & -0.0021 & 0.9300 & -38.8 \\
\hline O63 - H97 & 0.0175 & 0.0543 & 0.0139 & -0.0143 & -0.0003 & 0.9765 & -18.7 \\
\hline \multicolumn{8}{|c|}{ CHIT/DC2 } \\
\hline H37 - O73 & 0.0098 & 0.0307 & 0.0073 & -0.0069 & 0.0004 & 1.0573 & -9.0 \\
\hline H13 - O70 & 0.0073 & 0.0288 & 0.0062 & -0.0053 & 0.0010 & 1.1852 & -6.9 \\
\hline O41 - H90 & 0.0131 & 0.0388 & 0.0099 & -0.0100 & -0.0002 & 0.9828 & -13.2 \\
\hline H13 - O71 & 0.0106 & 0.0326 & 0.0079 & -0.0076 & 0.0003 & 1.0363 & -10.0 \\
\hline H36 - O71 & 0.0115 & 0.0368 & 0.0087 & -0.0082 & 0.0005 & 1.0604 & -10.8 \\
\hline N39 - H93 & 0.0364 & 0.0852 & 0.0233 & -0.0253 & -0.0020 & 0.9211 & -33.2 \\
\hline H53 - O73 & 0.0185 & 0.0593 & 0.0151 & -0.0153 & -0.0002 & 0.9846 & -20.1 \\
\hline N39 - H88 & 0.0094 & 0.0316 & 0.0070 & -0.0061 & 0.0009 & 1.1471 & -8.0 \\
\hline \multicolumn{8}{|c|}{ CHIT/DC3 } \\
\hline H34 - N77 & 0.0078 & 0.0312 & 0.0064 & -0.0050 & 0.0014 & 1.2800 & -6.6 \\
\hline O42 - H96 & 0.0162 & 0.0549 & 0.0137 & -0.0136 & 0.0001 & 1.0047 & -17.8 \\
\hline N18 - H97 & 0.0362 & 0.0897 & 0.0243 & -0.0262 & -0.0019 & 0.9275 & -34.4 \\
\hline O61 - H92 & 0.0047 & 0.0181 & 0.0036 & -0.0028 & 0.0009 & 1.3211 & -3.6 \\
\hline H38 - N75 & 0.0101 & 0.0373 & 0.0082 & -0.0071 & 0.0011 & 1.1535 & -9.3 \\
\hline H9 - O73 & 0.0089 & 0.0275 & 0.0064 & -0.0060 & 0.0004 & 1.0738 & -7.9 \\
\hline C84 - H91 & 0.0078 & 0.0314 & 0.0060 & -0.0042 & 0.0018 & 1.4270 & -5.6 \\
\hline O72 - H94 & 0.0127 & 0.0415 & 0.0100 & -0.0096 & 0.0004 & 1.0387 & -12.6 \\
\hline O41 - H91 & 0.0122 & 0.0368 & 0.0092 & -0.0092 & 0.0000 & 1.0029 & -12.0 \\
\hline O41 - H87 & 0.0100 & 0.0312 & 0.0074 & -0.0069 & 0.0004 & 1.0616 & -9.1 \\
\hline \multicolumn{8}{|c|}{ CHIT/DC4 } \\
\hline H37 - N77 & 0.0083 & 0.0250 & 0.0056 & -0.0049 & 0.0007 & 1.1441 & -6.4 \\
\hline H32 - N74 & 0.0086 & 0.0314 & 0.0067 & -0.0057 & 0.0011 & 1.1941 & -7.4 \\
\hline O72 - H94 & 0.0138 & 0.0448 & 0.0109 & -0.0106 & 0.0003 & 1.0298 & -13.8 \\
\hline N39 - H87 & 0.0092 & 0.0288 & 0.0065 & -0.0058 & 0.0007 & 1.1244 & -7.6 \\
\hline \multicolumn{8}{|c|}{ CHIT/DC5 } \\
\hline H31 - O73 & 0.0087 & 0.0297 & 0.0067 & -0.0060 & 0.0007 & 1.1242 & -7.8 \\
\hline H55 - N77 & 0.0060 & 0.0197 & 0.0042 & -0.0035 & 0.0007 & 1.1988 & -4.6 \\
\hline H55 - N75 & 0.0063 & 0.0211 & 0.0045 & -0.0037 & 0.0008 & 1.2148 & -4.8 \\
\hline H51 - N75 & 0.0111 & 0.0342 & 0.0077 & -0.0068 & 0.0009 & 1.1329 & -8.9 \\
\hline \multicolumn{8}{|c|}{ CHIT/DC6 } \\
\hline H55 - O71 & 0.0082 & 0.0277 & 0.0062 & -0.0054 & 0.0008 & 1.1413 & -7.1 \\
\hline O62 - H93 & 0.0319 & 0.0990 & 0.0253 & -0.0259 & -0.0005 & 0.9788 & -33.9 \\
\hline O68 - H86 & 0.0077 & 0.0302 & 0.0063 & -0.0051 & 0.0012 & 1.2384 & -6.7 \\
\hline O68 - H88 & 0.0079 & 0.0307 & 0.0064 & -0.0052 & 0.0013 & 1.2418 & -6.8 \\
\hline \multicolumn{8}{|c|}{ CHIT/DC7 } \\
\hline $\mathrm{H} 32$ - O70 & 0.0056 & 0.0246 & 0.0050 & -0.0039 & 0.0011 & 1.2879 & -5.1 \\
\hline N39 - H94 & 0.0086 & 0.0363 & 0.0073 & -0.0055 & 0.0018 & 1.3270 & -7.2 \\
\hline O68 - H92 & 0.0084 & 0.0300 & 0.0065 & -0.0054 & 0.0010 & 1.1909 & -7.1 \\
\hline N60 - H89 & 0.0083 & 0.0256 & 0.0056 & -0.0049 & 0.0008 & 1.1531 & -6.4 \\
\hline \multicolumn{8}{|c|}{ CHIT/DC8 } \\
\hline O41 - H96 & 0.0121 & 0.0410 & 0.0099 & -0.0095 & 0.0004 & 1.0413 & -12.4 \\
\hline H9 - N77 & 0.0073 & 0.0239 & 0.0052 & -0.0045 & 0.0007 & 1.1665 & -5.9 \\
\hline H9 - N75 & 0.0058 & 0.0196 & 0.0041 & -0.0033 & 0.0008 & 1.2384 & -4.3 \\
\hline H38 - N76 & 0.0357 & 0.0986 & 0.0256 & -0.0266 & -0.0010 & 0.9637 & -34.9 \\
\hline H67 - N75 & 0.0175 & 0.0541 & 0.0133 & -0.0131 & 0.0002 & 1.0157 & -17.2 \\
\hline O42 - H94 & 0.0115 & 0.0382 & 0.0091 & -0.0086 & 0.0005 & 1.0582 & -11.2 \\
\hline H9 - N77 & 0.0073 & 0.0239 & 0.0052 & -0.0045 & 0.0007 & 1.1665 & -5.9 \\
\hline H9 - N75 & 0.0058 & 0.0196 & 0.0041 & -0.0033 & 0.0008 & 1.2384 & -4.3 \\
\hline
\end{tabular}




\begin{tabular}{llllllll} 
H38 - N76 & 0.0357 & 0.0986 & 0.0256 & -0.0266 & -0.0010 & 0.9637 & -34.9 \\
H67 - N75 & 0.0175 & 0.0541 & 0.0133 & -0.0131 & 0.0002 & 1.0157 & -17.2 \\
O42 - H94 & 0.0115 & 0.0382 & 0.0091 & -0.0086 & 0.0005 & 1.0582 & -11.2 \\
\hline \multicolumn{7}{c}{ CHIT/DC9 } \\
\hline O64 - H96 & 0.0173 & 0.0592 & 0.0147 & -0.0146 & 0.0001 & 1.0071 & -19.1 \\
H35 - C85 & 0.0105 & 0.0408 & 0.0083 & -0.0064 & 0.0019 & 1.2909 & -8.4 \\
O72 - H94 & 0.0191 & 0.0555 & 0.0147 & -0.0155 & -0.0008 & 0.9471 & -20.3 \\
O41 - H87 & 0.0119 & 0.0392 & 0.0094 & -0.0089 & 0.0004 & 1.0483 & -11.7 \\
\hline & \multicolumn{7}{c}{ CHIT/DC10 } \\
\hline N18 - H96 & 0.0345 & 0.0814 & 0.0221 & -0.0238 & -0.0017 & 0.9270 & -31.3 \\
H38 - N77 & 0.0045 & 0.0177 & 0.0036 & -0.0028 & 0.0008 & 1.3021 & -3.6 \\
H34 - N76 & 0.0094 & 0.0344 & 0.0074 & -0.0063 & 0.0012 & 1.1855 & -8.2 \\
H56 - O72 & 0.0098 & 0.0368 & 0.0080 & -0.0067 & 0.0012 & 1.1839 & -8.8 \\
O63 - H92 & 0.0114 & 0.0338 & 0.0083 & -0.0082 & 0.0001 & 1.0165 & -10.7 \\
H35 - O72 & 0.0095 & 0.0358 & 0.0077 & -0.0065 & 0.0012 & 1.1849 & -8.6 \\
O64 - H95 & 0.0294 & 0.0925 & 0.0233 & -0.0235 & -0.0002 & 0.9920 & -30.8 \\
\hline
\end{tabular}

Table3

Quantum molecular descriptors (eV) for optimized geometries

\begin{tabular}{|c|c|c|c|c|c|c|c|c|c|c|c|}
\hline Species & $\mathrm{E}_{\text {НОмо }}$ & $\mathrm{E}_{\text {LUMO }}$ & $\mathrm{Eg}$ & $\eta$ & $\omega$ & Species & $\mathrm{E}_{\text {номо }}$ & $\mathrm{E}_{\text {LUMO }}$ & $\mathrm{Eg}$ & $\eta$ & $\omega$ \\
\hline \multicolumn{7}{|c|}{ B3LYP- $\mathrm{H}_{2} \mathrm{O}$} & \multicolumn{5}{|c|}{$\mathrm{M} 06-2 \mathrm{X}-\mathrm{H}_{2} \mathrm{O}$} \\
\hline $\mathrm{DC}$ & -6.94 & -0.98 & 5.96 & 2.98 & 2.63 & DC & -8.53 & 0.09 & 8.63 & 4.31 & 2.07 \\
\hline CHIT & -6.41 & 1.49 & 7.90 & 3.95 & 0.77 & CHIT & -8.16 & 2.69 & 10.85 & 5.42 & 0.69 \\
\hline CHIT/DC1 & -6.41 & -1.20 & 5.21 & 2.60 & 2.78 & CHIT/DC1 & -8.18 & -0.14 & 8.04 & 4.02 & 2.15 \\
\hline CHIT/DC2 & -6.46 & -1.05 & 5.41 & 2.70 & 2.61 & CHIT/DC2 & -8.22 & 0.02 & 8.24 & 4.12 & 2.04 \\
\hline CHIT/DC3 & -6.54 & -1.04 & 5.51 & 2.75 & 2.61 & CHIT/DC3 & -8.22 & 0.04 & 8.26 & 4.13 & 2.03 \\
\hline CHIT/DC4 & -6.41 & -0.99 & 5.42 & 2.71 & 2.53 & CHIT/DC4 & -8.19 & -0.11 & 8.08 & 4.04 & 2.13 \\
\hline CHIT/DC5 & -6.40 & -0.91 & 5.49 & 2.75 & 2.43 & CHIT & -8.18 & 0.14 & 8.32 & 4.16 & 1.94 \\
\hline CHIT/DC6 & -6.42 & -0.95 & 5.47 & 2.73 & 2.49 & CHIT/DC6 & -8.19 & 0.12 & 8.32 & 4.16 & 1.96 \\
\hline CHIT & -6.45 & -1.21 & 5.25 & 2.62 & 2.80 & CHIT & -8.19 & 0.11 & 8.30 & 4.15 & 1.97 \\
\hline CHIT/DC8 & -6.20 & -0.87 & 5.33 & 2.66 & 2.34 & CHIT/DC8 & -8.02 & 0.11 & 8.13 & 4.06 & 1.92 \\
\hline CHIT/DC9 & -6.51 & 1.18 & 5.33 & 2.67 & 2.77 & CHIT/DC9 & -8.22 & -0.27 & 7.95 & 3.97 & 2.26 \\
\hline CHIT/ & -6.53 & -0.95 & 5.58 & 2.79 & 2.51 & CHIT & -8.19 & 0.11 & 8.31 & 4.15 & 1.97 \\
\hline \multicolumn{7}{|c|}{ B3LYP-GAS } & \multicolumn{5}{|c|}{ M06-2X-GAS } \\
\hline $\mathrm{DC}$ & -6.61 & -0.77 & 5.84 & 2.92 & 2.34 & $\mathrm{DC}$ & -8.20 & 0.30 & 8.50 & 4.25 & 1.83 \\
\hline CHIT & -6.02 & 1.35 & 7.37 & 3.69 & 0.74 & CHIT & -7.97 & 2.60 & 10.39 & 5.19 & 0.65 \\
\hline CHIT/I & -5.96 & -1.22 & 4.74 & 2.37 & 2.72 & CHIT/ & -7.68 & -0.14 & 7.54 & 3.77 & 2.03 \\
\hline CHIT/DC2 & -6.06 & -0.91 & 5.15 & 2.57 & 2.36 & CHIT & -7.75 & 0.19 & 7.94 & 3.97 & 1.80 \\
\hline CHIT/DC3 & -6.20 & -0.61 & 5.59 & 2.80 & 2.07 & CHIT/DC3 & -7.96 & 0.32 & 8.28 & 4.14 & 1.77 \\
\hline CHIT/DC4 & -6.12 & -0.81 & 5.31 & 2.66 & 2.26 & CHIT/DC4 & -8.08 & 0.08 & 8.16 & 4.08 & 1.96 \\
\hline CHIT/DC5 & -5.60 & -0.63 & 4.97 & 2.48 & 1.95 & $\mathrm{CHI}^{-}$ & -7.79 & 0.66 & 8.45 & 4.23 & 1.50 \\
\hline CHIT/DC6 & -5.80 & -0.77 & 5.03 & 2.51 & 2.15 & CHIT & -7.81 & 0.62 & 8.43 & 4.21 & 1.53 \\
\hline CHIT/DC7 & -6.06 & -1.02 & 5.05 & 2.52 & 2.48 & CHIT/DC7 & -7.73 & 0.57 & 8.30 & 4.15 & 1.55 \\
\hline CHIT/DC8 & -5.87 & -0.82 & 5.04 & 2.52 & 2.22 & CHIT/DC8 & -7.65 & 0.39 & 8.05 & 4.02 & 1.64 \\
\hline CHIT/DC9 & -6.14 & -1.10 & 5.05 & 3.52 & 2.60 & & -7.91 & -0.01 & 7.90 & 3.95 & 1.98 \\
\hline CHIT/DC10 & -6.19 & -0.46 & 5.73 & 2.86 & 1.93 & CHIT/DC10 & -8.03 & 0.31 & 8.33 & 4.17 & 1.79 \\
\hline
\end{tabular}

Similar states are found for CHIT/DC9 and CHIT/DC6 $\quad\left(\sum_{i=1}^{e} E_{H E}^{i}=-59.5 \mathrm{kmol}^{-1}\right)$, $\sum_{\xi=1}^{Q} E_{H S}^{i}=-54.5 \mathrm{~mol}^{-1}$, where the $\mathrm{OH}$ and $\mathrm{N}$ functional groups of DC connect to $\mathrm{OH}$ and $\mathrm{NH}_{2}$ functional groups of CHIT, respectively. Probably the most unstable structure relates to CHIT/DC5 $\left(\sum_{i=1}^{\&} E_{H E}^{i}=-26.1 \mathrm{kJmol}^{-1}\right)$, where the $\mathrm{NH}_{2}$ functional group of DC approaches the $\mathrm{CH}_{2} \mathrm{OH}$ functional group of CHIT. The configuration has 4 weak interactions, 3 of which are related to $\mathrm{N}-\mathrm{H}$

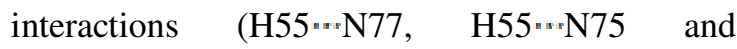
$\mathrm{H} 51 \cdots \mathrm{N} 75$ ).

In Table 3, quantum molecular descriptors (electrophilicity power $(\omega)$ and global hardness $(\eta))$ and $E_{g}$ gap of energy between LUMO (lowest unoccupied molecular orbital) and HOMO 
(highest occupied molecular orbital) for DC, CHIT and CHIT/DC1-10, at M06-2X and B3LYP levels, are described (in both phases).

Considering Table $3, E_{g}$ and $\eta$ of DC and CHIT/DC1-10 are almost identical. The parameters decreased in CHIT/DC1-10 structures. However, there is absolutely no considerable charge transfer between DC and CHIT. This is perfect for a drug delivery system, because the DC drug could be easily released from the exterior surface of this CHIT carrier. $E_{g}$ and $\eta$ values of CHIT/DC10 and CHIT/DC3 in aqueous solution are larger compared to those of other structures, which demonstrates that they are more stable than other structures. Because $\omega$ can be used to predict toxicity, it might be assumed that the toxicity of DC in the presence of CHIT will on average decrease.

\section{CONCLUSION}

Ten configurations of the non-bonded interactions of decitabine drug (DC) with chitosan (CHIT) nanocarrier were studied at B3LYP and M06-2X density functional levels in aqueous solution and gas phase (CHIT/DC1-10). The negative values of the binding energies demonstrated that the functionalization of CHIT with DC is energetically suitable. Solvation energies displayed that the solubility of DC increases in the presence of CHIT. Considering the electrophilicity power, the HOMO-LUMO energy gap and the global hardness, it may be assumed that the toxicity of DC in CHIT/DC1-10 will be reduced to some extent and its reactivity will increase. In addition, as shown by the AIM studies, the non-covalent adsorption of the drug on the carrier is mainly related to the hydrogen bonds. According to the AIM results, stronger and more hydrogen bonds exist in the most stable configuration (CHIT/DC10), where the $\mathrm{NH}_{2}$ and $\mathrm{N}$ functional groups of DC interacts with the $\mathrm{NH}_{2}$ and $\mathrm{OH}$ functional groups of CHIT, in the respective order.

ACKNOWLEDGEMENTS: We thank the Research Center for Animal Development Applied Biology for allocation of computer time.

\section{REFERENCES}

D. S. Spencer, A. S. Puranik and N. A. Peppas, Curr. Opin. Chem. Eng., 7, 84 (2015), https://doi.org/10.1016/j.coche.2014.12.003
2 M. Kamel, H. Raissi, A. Morsali and M. Shahabi, Appl. Surf. Sci., 434, $492 \quad$ (2018), https://doi.org/10.1016/j.apsusc.2017.10.165

3 M. Lotfi, A. Morsali and M. R. Bozorgmehr, Appl. Surf. Sci., 462, $720 \quad$ (2018), https://doi.org/10.17586/2220-8054-2019-10-4-438446

4 S. Hamedani, S. Moradi and H. Aghaie, Chinese J. Struct. $\quad$ Chem., 34, $1161 \quad$ (2015), http://doi.org/10.13005/ojc/330309

5 A. Chauhan, Molecules, 23, 938 (2018), https://doi.org/10.3390/molecules23040938

6 B. S. Pattni, V. V. Chupin and V. P. Torchilin, Chem. Rev., 115, 10938 (2015), https://doi.org/10.1021/acs.chemrev.5b00046

7 N. Marasini, S. Haque and L. M. Kaminskas, Curr. Opin. Colloid Interface Sci., 31, 18 (2017), https://doi.org/10.1016/j.cocis.2017.06.003

${ }^{8}$ K. Raza, N. Thotakura, P. Kumar, M. Joshi, S. Bhushan et al., Int. J. Pharm., 495, 551 (2015), https://doi.org/10.1016/j.ijpharm.2015.09.016

9 S. K. Shukla, A. K. Mishra, O. A. Arotiba and B. B. Mamba, Int. J. Biol. Macromol., 59, 46 (2013), https://doi.org/10.1016/j.ijbiomac.2013.04.043

10 A. Ali and S. Ahmed, Int. J. Biol. Macromol., 109, 273

(2018),

https://doi.org/10.1016/j.ijbiomac.2017.12.078

11 H. S. Adhikari and P. N. Yadav, Int. J. Biomater., 2018 , 2952085

(2018), https://doi.org/10.1155/2018/2952085

12 R. Shanmuganathan, T. N. J. I. Edison, F. L. Oscar and K. Ponnucha, Int. J. Biol. Macromol., 130, 727 (2019), https://doi.org/10.1016/j.ijbiomac.2019.02.060

13 R. Nicu, E. Bobu and J. Desbrieres, Cellulose Chem. Technol., 45, $105 \quad$ (2011), https://www.cellulosechemtechnol.ro/pdf/CCT12(2011)/p.105-111.pdf

14 M. Wu, W. Lv, F. Wang, Z. Long, J. Chen et al., Cellulose Chem. Technol., 52, 43 (2018), https://www.cellulosechemtechnol.ro/pdf/CCT12(2018)/p.43-49.pdf

15 A. Kumari, S. K. Yadav, Y. B. Pakade and B. Singh, Colloids Surf. B, 80, 184 (2010), https://doi.org/10.1016/j.colsurfb.2010.06.002

16 L. Andze, J. Zoldners, L. Rozenberga, I. Sable, M. Skute et al., Cellulose Chem. Technol., 52, 873 (2018), https://www.cellulosechemtechnol.ro/pdf/CCT910(2018)/p.873-881.pdf

17 F. Akman, Cellulose Chem. Technol., 51, 253 (2017),

https://www.cellulosechemtechnol.ro/pdf/CCT34(2017)/p.253-262.pdf

18 X.-F. Zheng, Q. Lian, H. Yang and X. Wang, Sci. Rep., $\quad 6, \quad 21409 \quad$ (2016), https://doi.org/10.1038/srep21409

19 P. Li, Y. Wang, Z. Peng, F. She and L. Kong, Carbohydr. Polym., 85, $698 \quad$ (2011), https://doi.org/10.1016/j.carbpol.2011.03.045 
20 A. Nawaz and T. W. Wong, J. Investig. Dermatol., 138, $2412 \quad$ (2018), https://doi.org/10.1016/j.jid.2018.04.037

21 H. Horo, S. Das, B. Mandal and L. M. Kundu, Int. J. Biol. Macromol., 121, $1070 \quad$ (2019), https://doi.org/10.1016/j.ijbiomac.2018.10.095

22 K. Yoncheva, M. Merino, A. Shenol, N. T. Daskalov, P. S. Petkov et al., Int. J. Pharm., 556, 1 (2019), https://doi.org/10.1016/j.ijpharm.2018.11.070

23 A. Khdair, I. Hamad, H. Alkhatib, Y. Bustanji, M. Mohammad et al., Eur. J. Pharm. Sci., 93, 38 (2016), https://doi.org/10.1016/j.ejps.2016.07.012

24 A. V. Nascimento, A. Singh, H. Bousbaa, D. Ferreira, B. Sarmento et al., Acta Biomater., 47, 71 (2017), https://doi.org/10.22034/nmrj.2017.62889.1065 25 M. Moura, M. Gil and M. Figueiredo, Eur. Polym. $\begin{array}{llll}J ., & 49, & 2504 & \text { (2013), }\end{array}$ https://doi.org/10.1021/bm200731x

26 A. Portero, C. Remunan-Lopez and J. Vila-Jato, Int. J. Pharm., 175, $75 \quad$ (1998), https://doi.org/10.1007/s13233-010-1004-0

27 N. T. Chinh, N. T. T. Trang, N. V. Giang, D. T. M. Thanh, T. T. X. Hang et al., J. Appl. Polym. Sci., 133 (2016), https://doi.org/10.1007/s10924-020-01727-6

28 L. P. Jahromi, F. M. Panah, A. Azadi and H. Ashrafi, Int. J. Biol. Macromol., 125, 785 (2019), https://doi.org/10.3390/biomedicines8010013

29 A. Alexander, S. Saraf and S. Saraf, Drug Dev. Ind. Pharm., 41, 1954 (2015), https://doi.org/10.3109/03639045.2015.1011167

30 M. Nag, V. Gajbhiye, P. Kesharwani and N. K. Jain, Colloids Surf. B, 148, 363 (2016), https://doi.org/10.1016/j.colsurfb.2016.08.059

31 E. Lee, J. Lee, I.-H. Lee, M. Yu, H. Kim et al., J. Med. Chem., 51, $6442 \quad$ (2008), https://doi.org/10.1021/jm800767c

32 S. Natesan, C. Ponnusamy, A. Sugumaran, S. Chelladurai, S. S. Palaniappan et al., Int. J. Biol. Macromol., $\quad \mathbf{1 0 4}, \quad 1853 \quad$ (2017), https://doi.org/10.1016/j.ijbiomac.2017.03.137

33 J.-B. Qu, H.-H. Shao, G.-L. Jing and F. Huang,

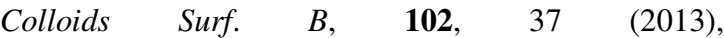
https://doi.org/10.1016/j.colsurfb.2012.08.004

34 S. A. Agnihotri and T. M. Aminabhavi, Int. J. Pharm., 324, 103 (2006), https://doi.org/10.1016/j.ijpharm.2006.05.061

35 R. Mo, Y. Xiao, M. Sun, C. Zhang and Q. Ping, Int. J. Pharm., 409, 38 (2011), https://doi.org/10.1016/j.ijpharm.2011.02.021

36 G. Arya, M. Vandana, S. Acharya and S. K. Sahoo, Nanomedicine, $\quad 7, \quad 859 \quad$ (2011), https://doi.org/10.1016/j.nano.2011.03.009

37 W. J. Trickler, J. Khurana, A. A. Nagvekar and A. K. Dash, Aaps. Pharm. Sci. Tech., 11, 392 (2010), https://doi.org/10.1208/s12249-010-9393-0

38 H. Zheng, Y. Rao, Y. Yin, X. Xiong, P. Xu et al., Carbohyd. Polym., 83, $1952 \quad$ (2011), https://doi.org/10.1016/j.carbpol.2010.10.069
39 Y. S. Elnaggar, S. M. Etman, D. A. Abdelmonsif and O. Y. Abdallah, J. Pharm. Sci., 104, 3544 (2015), https://doi.org/10.1002/jps.24557

40 A. Dev, N. Binulal, A. Anitha, S. Nair, T. Furuike et al., Carbohyd. Polym., 80, 833 (2010), https://doi.org/10.1016/j.carbpol.2009.12.040

41 S. Kamalzare, Z. Noormohammadi, P. Rahimi, F. Atyabi, S. Irani et al., J. Cell. Physiol., 234, 20554 (2019), https://doi.org/10.1002/jcp.28655

${ }^{42}$ W. Kunanusornchai, B. Witoonpanich, T. Tawonsawatruk, R. Pichyangkura, V. Chatsudthipong et al., Pharmacol. Res., 113, 458 (2016), https://doi.org/10.1016/j.phrs.2016.09.016

${ }^{43}$ S. Li, S. Cui, D. Yin, Q. Zhu, Y. Ma et al., Nanoscale, $\quad 9, \quad 3912 \quad$ (2017), https://doi.org/10.1039/C6NR07188K

44 N. Saikia and R. C. Deka, J. Struct. Chem., 25, 593 (2014), https://doi.org/10.1007/s11224-013-0327-9

45 H. Chegini, A. Morsali, M. Bozorgmehr and S. Beyramabadi, Prog. React. Kinet. Mec., 41, 345 (2016), http://dx.doi.org/10.13005/ojc/310318

46 H. Xu, L. Li, G. Fan and X. Chu, Comput. Theor. Chem., $\quad$ 1131, $57 \quad$ (2018), https://doi.org/10.1016/j.comptc.2018.03.032

47 H. Lari, A. Morsali and M. M. Heravi, Nanosystems: Physics, Chemistry, Mathematics, 10, 438 (2019), https://doi.org/10.17586/2220-8054-202011-3-285-293

${ }^{48}$ M. Frisch, G. Trucks, H. Schlegel, G. Scuseria, M. Robb et al., Gaussian 09, revision B.01. Gaussian, Inc., Wallingford, CT (2009), https://gaussian.com

${ }^{49}$ Y. Zhao and D. G. Truhlar, Theor. Chem. Acc., 120, 215 (2008), https://doi.org/10.1007/s00214-007-0310$\mathrm{X}$

50 J. D. Dill and J. A. Pople, J. Chem. Phys., 62, 2921 (1975), https://doi.org/10.1063/1.430801

51 A.D. Becke, J. Chem. Phys., 98, 5648 (1993), https://doi.org/10.1007/s002149900065

52 J. Tomasi and M. Persico, Chem. Rev., 94, 2027 (1994), https://doi.org/10.1021/cr00031a013

53 E. L. Coitiño, J. Tomasi and R. Cammi, J. Comput. Chem., $\quad \mathbf{1 6}, \quad 20 \quad$ (1995), https://doi.org/10.1002/jcc.540160103

54 R. G. Parr, L. V. Szentpaly and S. Liu, J. Am. Chem. Soc., 121, $1922 \quad$ (1999), https://doi.org/10.1021/ja983494x

55 T. A. Keith and T. K. Gristmill, Software, Overland Park KS, USA (2013), http://aim.tkgristmill.com

56 R. F. Bader, Chem. Rev., 91, 893 (1991), https://doi.org/10.1021/cr00005a013

57 Y. Zhao and D. G. Truhlar, Theor. Chem. Acc., 120, 215 (2008), https://doi.org/10.1063/1.2912068

58 B. C. Deka and P. K. Bhattacharyya, Comput. Theor. Chem., 1110, 40 (2017), https://doi.org/10.1016/j.comptc.2017.03.036

59 B. C. Deka and P. K. Bhattacharyya, Comput. Theor. Chem., 1051, $35 \quad$ (2015), https://doi.org/10.1016/j.comptc.2014.10.023 


\section{MAHNAZ RAHBAR et al.}

60 M. Nasrabadi, S. A. Beyramabadi and A. Morsali, Int. J. Biol. Macromol., 147, 534 (2020), https://doi.org/10.1016/j.ijbiomac.2020.01.070

${ }^{61}$ P. Geetha, A. J. Sivaram, R. Jayakumar and C. G. Mohan, Carbohyd. Polym., 142, 240 (2016), https://doi.org/10.1016/j.carbpol.2016.01.059

62 S.-H. Lin, W. Cui, G.-L. Wang, S. Meng, Y.-C. Liu et al., Drug Des. Devel. Ther., 10, 2973 (2016), https://doi.org/10.2147/DDDT.S114663

63 F. Naghavi, A. Morsali and M. R. Bozorgmehr, $J$. Mol. Liq., 282, $392 \quad$ (2019), https://doi.org/10.1016/j.molliq.2019.03.040

${ }^{64}$ I. Rozas, I. Alkorta and J. Elguero, J. Am. Chem. Soc., 122, 11154 (2000), https://doi.org/10.1021/ja0017864 